\title{
PABLO NERUDA, POESÍA Y POLÍTICA
}

TEODOSIO FERNÁNDEZ

1

Confieso que he vivido. Memorias, Barcelona, Seix Barral, 1974, pág. 371. Para evitar notas innecesarias, tras cada cita de este libro aparecerán en adelante las siglas $C V$, seguidas de la página correspondiente.

2

Véase Discursos parlamentarios de Pablo Neruda (1945-1948), edición de Leonidas Aguirre Silva, prólogo de Volodia Teitelboim e introducción de Abraham Quezada Vergara, Santiago de Chile, 1997, págs. 298-299. En adelante las citas de este volumen aparecerán seguidas de las siglas DP y el número de la página correspondiente.

Pablo Neruda, poesía y política TEODOSIO FERNÁNDEZ
Sin ignorar las inquietudes iniciales que Pablo Neruda alentó en Temuco y Santiago — «yo me sumé de inmediato a la ideología anarcosindicalista estudiantil», recordará al evocar la vida literaria de su juventud ${ }^{1}-$, sin duda la guerra civil española resultó decisiva para el desarrollo de sus preocupaciones políticas. Desde España en el corazón (1937) hasta Incitación al nixonicidio y alabanza de la revolución chilena (1973) había de ofrecer una producción literaria que difícilmente puede entenderse al margen de las circunstancias de cada momento, incluso cuando parece totalmente ajena a ellas. Algunas han sido ya suficientemente comentadas, pero otras quizá merecen análisis que ayuden a precisar mejor la significación de su poesía y del proceso que siguió. La publicación reciente de sus discursos parlamentarios invita a volver sobre ese período, que para él supuso la etapa de mayor dedicación a la actividad política en sentido estricto. Se inició con la campaña que lo llevó a ser elegido senador el 4 de marzo de 1945, por la Primera Circunscripción Provincial de Tarapacá y Antofagasta. Concluiría el 28 de mayo de 1950, cuando Radomiro Tomic Romero fue elegido para cubrir la vacante dejada por Neruda «por haberse ausentado del territorio de la República»².

El 8 de julio de 1945, en un acto celebrado en el Teatro Caupolicán de Santiago, el poeta formalizó su ingreso en el Partido Comunista, a la vez que lo hacían el músico Armando Carvajal y los escritores Nicomedes Guzmán, Francisco Coloane y Ángel Cruchaga. Ya en Madrid había descubierto en los comunistas la única fuerza organizada para luchar contra el fascismo, y sus preferencias se fueron precisando durante su estancia como cónsul en
México. Las orientó también el Partido Comunista de Chile, que le mostró su solidaridad y su apoyo en ocasiones señaladas: cuando sufrió la agresión de algunos nazis en Cuernavaca, el 21 de diciembre de 1941, y cuando tuvo problemas en el Consulado por la «Dura elegía» que el 18 de junio de 1943 había leído en los funerales de la madre de Luis Carlos Prestes, un ataque contra Getulio Vargas, presidente del Brasil, que provocó una reclamación de la cancillería brasileña ante el gobierno chileno. De los comunistas partió también la invitación a figurar en la lista de candidatos parlamentarios por la Coalición Progresista Nacional. Consecuente con los planteamientos del partido, desde que fue proclamado senador, el 13 de mayo de 1945, Neftalí Ricardo Reyes Basoalto —su seudónimo no ingresó de inmediato en el Boletín de Sesiones-desarrollaría una notable actividad parlamentaria en la que se mantuvieron constantes su preocupación por las clases populares chilenas - sobre todo por las masas obreras del norte del país, que lo habían elegido-, su defensa de la Unión Soviética y de las relaciones con los países socialistas, y su atención a los acontecimientos que afectaban a una Latinoamérica torturada entonces por Higinio Morínigo en Paraguay, por Rafael Leónidas Trujillo en la República Dominicana, por Tiburcio Carías en Honduras, por Juan Domingo Perón en Argentina. Cabe suponer que se sintió especialmente cómodo al abordar algún tema de carácter cultural, sobre todo al celebrar el 20 de noviembre de 1945 el Premio Nobel concedido a Gabriela Mistral.

La actuación parlamentaria de Neruda no tardó en resultar conflictiva. El poeta empezó 
a mostrarse polémico cuando en junio de 1946 reprochó al gobierno la persecución iniciada contra el republicano español Antonio Aparicio. Por otra parte, la muerte del presidente Juan Antonio Ríos, en julio de ese año, hizo que entrase decididamente en su vida Gabriel González Videla, del Partido Radical, cuya campaña para la presidencia apoyó como miembro del Partido Comunista y en calidad de Jefe Nacional del Comité de Propaganda. Compartieron el triunfo electoral el 4 de septiembre de 1946, pero en junio de 1947, cuando González Videla responsabilizó al Partido Comunista de una huelga de los conductores y cobradores de autobuses, Neruda le recordó que había llegado al poder con apoyo de las fuerzas democráticas, entre las que se habían contado los militantes comunistas, y exigió el cumplimiento de sus promesas electorales. «Fue amado como pocos mandatarios antes de él y despreciado, cuando traicionó a su pueblo, como ninguno» (DC, 159), declaraba refiriéndose al derrocado presidente del Ecuador, José María Velasco Ibarra, el 26 de agosto de 1947. «Del Ecuador, país hermano que tanto admiró nuestra democracia popular y nuestras instituciones, nos llega esta lección política, profética y profunda» (DC, 160), añadía, para dejar claro que pensaba en la situación política chilena. Su ruptura definitiva con González Videla llegó con la huelga del carbón que afectó a Lota, Coronel y otros centros mineros, y que el 4 de octubre alcanzó su momento más tenso. González Videla había iniciado la persecución del Partido Comunista, al que trató de eliminar de la escena política nacional, a la vez que rompía relaciones con la Unión Soviética, Yugoslavia y Checoslovaquia.

El 14 de octubre Neruda atacó directamente al presidente, al que acusaba de haber traicionado a sus electores y de impedir la solución de la huelga del carbón, y contribuyó a que la tensión se acentuara aún más cuando El Nacional de Caracas publicó el 27 de noviembre su "Carta íntima para millones de hombres", reproducida también en El Popular de México y quizá en algún otro periódico latinoamericano. Trataba de informar a sus amigos del continente sobre la situación que vivía la tradición democrática chilena, «hoy aplastada y deshecha por la obra conjugada de la presión extranjera y la traición política de un presidente elegido por el pueblo» ${ }^{3}$. No hacía sino reiterar las denuncias que había hecho ante el Senado de su país, pero González Videla pidió a los Tribunales de Justicia su desafuero como senador. Aunque ya el 23 de diciembre Neruda se defendió de las acusaciones de antipatriotismo o de traición al país — «Chile no es el Excelentísimo señor González Videla» (DP, 228), pudo resumir-, su respuesta fue otro célebre "Yo acuso" el 6 de enero de 1948, discurso en que el presidente resultó culpable de hacer de Chile un país con centenares de presos políticos, con los trabajadores condenados a la cesantía y a la miseria, con la prensa y la radio censuradas, con relaciones exteriores frívolas e inconsecuentes, y supeditado por completo a los intereses políticos y económicos norteamericanos. El 3 de febrero la Corte Suprema aprobaba su desafuero, acusado de proferir injurias contra el presidente del país en periódicos extranjeros, y el 5 los tribunales de justicia procedieron a ordenar su detención. Así iniciaba Neruda el período de clandestinidad que se prolongó hasta febrero de 1949, cuando cruzó la frontera en la zona de los lagos para irse al exilio 4 .

La actividades parlamentarias de Neruda constituyen un testimonio elocuente de la sinceridad de su compromiso político, de la pasión con que lo asumió e incluso de los esfuerzos que hizo para hacer suya la doctrina del Partido Comunista ${ }^{5}$. Esa entrega determinó en buena medida el rumbo de su poesía, que no dejó de ser profundamente personal. «Creo que tanto Residencia en la tierra, libro sombrío y esencial dentro de mi obra, como Las uvas y el viento, libro de grandes espacios y mucha luz, tienen derecho a existir en alguna parte» (CV, 405), reclamaría el poeta, muy consciente de la oposición que se veía entre su poesía residenciaria (con sus consecuencias posteriores) y su poesía política, destinataria esta última de la mayor parte de las críticas adversas. No era menos auténtico o sincero ahora que hablaba de los demás que cuando había hablado de sí mismo. Es más, en Canto general habló sobre todo de sí mismo y de la experiencia política que había vivido. «Si quisiera injuriar al Presidente de la República, lo haría dentro de mi obra literaria. Pero, si me veo obligado a tratar su caso en el vasto poema titulado Canto general de Chile, que escribo actualmente cantando la tierra y
3

«La crisis democrática de Chile es una advertencia dramática para nuestro continente», en Pablo Neruda, Para nacer he nacido, Barcelona, Seix Barral, 1978, págs. 287-311 (287).

4

El 2 de junio de 1948 el Senado mantuvo su derecho a percibir la dieta de senador, aunque estuviese desaforado, y durante algún tiempo se lo consideró ausente con permiso oficial (DC, 291, 297-298).

5

Véase su aprovechamiento de Marx y Engels al defender los derechos políticos de la mujer (10 de diciembre de 1946) en DP, 104-114.
Pablo Neruda, poesía y política TEODOSIO FERNÁNDEZ 
Obras completas, Buenos Aires, Losada, cuarta edición aumentada, 1973, I, págs. 368-369.

\section{7}

Véase Rafael Alberti, La arboleda perdida, segunda parte, Barcelona, Círculo de Lectores, 1988, pág. 287.

\section{8}

Las uvas y el viento, en Obras completas, l, pág. 813.

\section{9}

Fin de mundo, Buenos Aires, Losada, $2^{a}$ edición, 1970, pág. 180. Las citas de este poemario aparecerán en adelante seguidas de las siglas FM y el número de página correspondiente.
Pablo Neruda, poesía y política TEODOSIO FERNÁNDEZ los episodios de nuestra patria, lo haré también con la honradez y la pureza que he puesto en mi actuación política» (DP, 255), había declarado al pronunciar su "Yo acuso". Lo cierto es que el Canto general fue consecuencia en gran medida de esas experiencias, pues casi todo en él deriva finalmente hacia la denuncia del régimen político de González Videla y sus cómplices, y hacia la manifestación de la solidaridad con sus víctimas. El lector puede comprobarlo al menos desde el canto III, cuando la referencia a los «usureros de Euzkadi, nietos / de Loyola» que se repartieron Chile, va encaminada a incluir entre los depredadores a «los Errázuriz / que llegaron con su escudo de armas, / un látigo y una alpargata» ${ }^{6}$, y por tanto al senador liberal Ladislao Errázuriz Pereira, enemigo declarado del poeta.

El proceso poético de los años cincuenta había de mostrar también lo profundamente imbricadas que se hallaban las circunstancias políticas y personales de Neruda con el desarrollo de su poesía. Incluso el paso de Delia del Carril, «el ojo de Molotov»', a Matilde Urrutia, destinataria de los Versos del capitán, concuerda con los cambios que se harían evidentes a lo largo de la década, y quizá los preparaba. Algunos acontecimientos resultarían sin duda determinantes, y entre ellos debe recordarse la muerte de Stalin, cuya noticia se difundió el 6 de marzo de 1953. Neruda le dedicaría "Es ancho el nuevo mundo", donde veló «al Capitán lejano que al entrar en la muerte / dejó a todos los pueblos, como herencia, su vida» ${ }^{8}$. Poco después, a partir del 26 de abril, se celebraba en Santiago de Chile un Congreso Continental de la Cultura, donde la figura del dirigente desaparecido no se discutió. En diciembre de aquel año, Neruda recibiría el Premio Stalin por la Paz y la Amistad entre los Pueblos. Le hubiera resultado difícil hacerlo a partir de 1956, desde que Nikita Jruschor aprovechó el XX Congreso del Partido Comunista de la Unión Soviética para criticar el culto a la personalidad y denunciar los crímenes cometidos bajo el régimen stalinista. El poeta guardó entonces un disciplinado silencio, que prolongó cuando en noviembre de ese año las tropas soviéticas aplastaron la insurrección de Hungría (con el episodio final del fusilamiento de Imre Nagy ya en 1958), y que mantenía aún cuando en la tercera semana de agosto de 1968 los tanques del Pacto de Varsovia pusieron fin a la primavera de Praga.

En sus memorias, sin embargo, dejó constancia de la tragedia que significó para los comunistas descubrir que «en diversos aspectos del problema Stalin, el enemigo tenía razón», y de su voluntad de extraer consecuencias positivas de la sombría noche que terminó siendo la siniestra época stalinista: «Si bien es cierto que esa responsabilidad nos alcanzaba a todos, el hecho de denunciar aquellos crímenes nos devolvía a la autocrítica y al análisis -elementos esenciales de nuestra doctrina- y nos daba las armas para impedir que cosas tan horribles pudieran repetirse» (CV, 435-436). También, al recordar su estancia de 1957 en China, señalaba que no había sido Mao Tse Tung quien lo había distanciado del proceso político que vivía aquel país, sino «el maosetunismo. Es decir, el maoestalinismo, la repetición del culto a una deidad socialista» (CV, 330). Sin duda se sintió afectado por los procesos políticos de que empezaban a ser víctimas sus amigos escritores. Aunque su poesía evitara las referencias directas a esas experiencias, tampoco podría defender sus convicciones con la seguridad y el optimismo de años anteriores. Las consecuencias de esa crisis pueden encontrarse en las dudas del Tercer libro de las odas, en la irreverencia de Estravagario, en la voluntad de hacer balance que se concretó en Memorial de Isla Negra.

Sólo en Fin de mundo se decidió Neruda — «el hombre sonoro / testigo de la esperan$\mathrm{za} /$ de este siglo asesinado»'- a dejar constancia expresa de las preocupaciones políticas que lo asediaban. Sin duda su militancia comunista se mantenía inalterada, al tiempo que la guerra de Vietnam le daba nuevas razones poderosas para atacar a Estados Unidos. Pero sus esperanzas en la revolución «idolatrada» se veían sujetas a los avatares de la época. Es probable que los sucesos de Checoslovaquia lo afectasen profundamente — «la hora de Praga me cayó / como una piedra en la cabeza» (FM, 20)—, acentuando una desorientación que ya venía de lejos, determinada por la obligación de callar ante los muchos y graves errores cometidos — «sufrimos de no defender / la flor que se nos amputaba / para salvar el árbol rojo / que necesita crecimiento» (FM, 21) - en aras de la empresa revolucionaria. Los momentos más dolo- 
rosos coincidieron probablemente con la revelación de los crímenes de Stalin y de las consecuencias del culto a la personalidad — «ue la proliferación / de aquel impasible retrato / la que incubó lo desmedido» (FM, 109) —, reiteradas después en un nuevo rostro multiplicado en los retratos, el de Mao Tse Tung, otra deidad que pensó por todos y encarnó un poder absoluto.

Entre las preocupaciones políticas de sus últimos años, la revolución cubana ocupó un lugar de privilegio. Antes de viajar hasta la isla, a fines de 1960, Neruda dedicó Canción de gesta «a los libertadores de Cuba: Fidel Castro, sus compañeros y el pueblo cubano ${ }^{10}$, pero también a quienes en Puerto Rico y todo el ámbito del Caribe (países centroamericanos, Colombia, Venezuela) combatían por su libertad frente a Estados Unidos, y que constituían también el tema del libro. Su "Meditación sobre la Sierra Maestra" lo mostró consciente del profundo significado de lo ocurrido: «en esta hora mi razón nocturna / señala en Cuba la común bandera / del hemisferio oscuro que esperaba / por fin una victoria verdadera» (CG, 74). Pero la visión épica de la revolución no impedía advertir las reticencias ante el peligro de una nueva concentración del poder. «...Tu victoria / es como el viejo vino de mi patria: / no lo hace un hombre sino muchos hombres / y no una uva sino muchas plantas: / y no es una gota sino muchos ríos: / no un capitán sino muchas batallas» (CG, 28), advertía el poeta a Fidel, al ofrecerle una copa de vino chileno. Sin duda se sintió más cerca de Ernesto Che Guevara, lector obstinado de Canto general, pero no ocultó su opinión negativa de los movimientos guerrilleros que olvidaban la lucha en favor de las clases explotadas por el capitalismo, y reservaban el poder para los grupos armados en la hora de su triunfo. «El vicio de este razonamiento — aclaró- es su debilidad política: puede ser que en algunas ocasiones el gran guerrillero coexista con una poderosa personalidad política, como en el caso del Che Guevara, pero eso es una cuestión minoritaria y de azar. Los supervivientes de una guerrilla no pueden dirigir un estado proletario por el solo hecho de ser más valientes, de haber tenido mejor suerte frente a la muerte o mejor puntería frente a los vivos» (CV, 453).

En las reticencias de Neruda influyó sin duda un episodio conocido y enojoso: la car- ta abierta «al compañero Pablo» en que se criticó su viaje a Nueva York para participar en una Conferencia del Pen Club Internacional, en junio de 1966, y la Orden del Sol del Perú con que lo condecoró en Lima el presidente Fernando Belaúnde. En esa carta - al parecer redactada por Lisandro Otero, Roberto Fernández Retamar y Edmundo Desnoes, y publicada en el periódico Granma el 31 de julio de 1966- quedaban de manifiesto las inquietudes que sus viajes despertaban en la isla: «... es evidente, Pablo — se decía-, que quienes se benefician con estas últimas actividades tuyas, no son los revolucionarios latinoamericanos; ni tampoco los negros norteamericanos, por ejemplo: sino quienes propugnan la más singular coexistencia, a espaldas de las masa de desposeídos, a espaldas de los luchadores» ${ }^{11}$. Neruda se sintió agredido, y eso quizá determinó para siempre sus diferencias con la revolución cubana. «Cuando todo estaba ganado / se asociaron los escribientes / y acumularon firmadores: / todos ellos se acorralaron / disparando contra mi voz, / contra mi canto cristalino / y mi corazón comunista», escribió en Fin de mundo (52-53), donde a pesar de todo mantenía la visión épica de la victoria conseguida. «Ya no me acuerdo de los términos empleados por mis fiscales. Pero puedo decir que se erigían en profesores de las revoluciones, en dómines de las normas que deben regir a los escritores de izquierda. Con arrogancia, insolencia y halago, pretendian enmendar mi actividad poética, social y revolucionaria» ( $\mathrm{CV}, 445)$, recordaría en sus memorias, y también que en el comité central alguien lo interpretó como un ataque al Partido Comunista de Chile, dentro de los conflictos que por entonces enfrentaron a algunos partidos comunistas latinoamericanos con la revolución cubana.

Cualquiera que sea la relación que guarde con ese desencuentro, merece atención el proceso que en los años sesenta llevó a la poesía hispanoamericana por caminos que la alejaban de Neruda. "Todos los que nerudearon / comenzaron a vallejarse / y antes del gallo que cantó / se fueron con Perse y con Eliot / y murieron en su piscina», escribió el poeta en Fin de mundo (97), muy consciente de lo que ocurría. «En los últimos tiempos, en esta pequeña guerra de la literatura, guerra mantenida por pequeños soldados de dientes feroces -había de confirmar en sus memorias-,
10

Canción de gesta, La Habana, Imprenta Nacional de Cuba (Ediciones de la Casa de las Américas), 1960, pág. 1. En adelante las citas de este poemario irán seguidas de las siglas CG y el número de página correspondiente.

11

"Carta abierta a Pablo Neruda", Casa de las Américas, año VI, núm. 38, septiembre-octubre de 1966, págs. 131-135 (133).
Pablo Neruda, poesía y política TEODOSIO FERNÁNDEZ 
12

Véase Saúl Yurkievich, Poesía hispanoamericana 1960-1970. Antología a través de un certamen continental, México, Siglo XXI Editores, $2^{g}$ edición 1976 (191972), pág. 7

\section{3}

Dios trajo la sombra, en Los cuadernos de la tierra I-IV, Quito, Casa de la Cultura Ecuatoriana, 1963, pág. 65.

\section{4}

La poesía hispanoamericana 1960-1970, pág. 7.

\section{5}

Jorge Edwards, Adiós, Poeta..., Barcelona, Tusquets, 1990, pág. 17.

16

El atentado tuvo lugar en mayo de 1940. Neruda, que llegó a la capital mexicana el 16 de agosto de ese año, declararía haber conocido a Alfaro Siqueiros en prisión (CV, 218). Tal vez no era así: según Jorge Edwards (op. cit., págs. 279-280), en el libro de visitas del restaurante Luis XIV, en la Place des Victoires de París, pudo ver la firma de ambos y la de André Malraux, testimonio de algún encuentro ocurrido en 1939.
Pablo Neruda, poesía y política TEODOSIO FERNÁNDEZ han estado lanzando a Vallejo, a la sombra de César Vallejo, a la ausencia de César Vallejo, a la poesía de César Vallejo, contra mí y mi poesía» (CV, 391). Al analizar los once primeros poemarios galardonados con el Premio Casa de las Américas, Saúl Yurkievich señaló el «pasaje de los nerudeanos a los vallejeanos» como uno de los rasgos comunes o «líneas de fuerza» de la poesía de aquellos años ${ }^{12}$. Las exigencias políticas y culturales de la revolución excluían de antemano a los que no se atenían a ellas, e inevitablemente se prestaba atención a quienes en la isla (como el cubano Fayad Jamís, ganador en 1962 con Por esta libertad) se ajustaban a las circunstancias derivadas del triunfo revolucionario, o a quienes, fuera del país (como el salvadoreño Roque Dalton, galardonado en 1969 por Taberna y otros lugares), habían sufrido experiencias políticas que los habían llevado a abandonar una poesía egocéntrica y celeste en favor de otra de denuncia y protesta, acorde también con los avances del coloquialismo y del prosaísmo característicos de la época. Más significativo resulta que sólo en los primeros años se galardonase a herederos de Neruda: Dios trajo la sombra, del ecuatoriano Jorge Enrique Adoum (premiado en 1960), y El gran cacique, del venezolano Alí Lameda (premiado en 1963), eran consecuencias evidentes de Canto general, de su interpretación

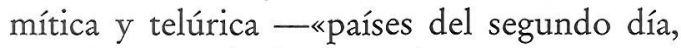
creación inacabada, húmedos, / sin tiempo para secarse todavía», en opinión de Adoum ${ }^{13}$ - de una América en permanente lucha por su libertad. Por el contrario, El uso de la palabra, del argentino Mario Trejo (premiado en 1964), Oíd, mortales, del también argentino Víctor García Robles (premiado en 1965), y Diario de cuartel, del uruguayo Carlos María Gutiérrez (premiado en 1970), mostraban una acusada proclividad hacia Vallejo, de cuya recuperación caben diversas interpretaciones. Parece evidente que fue utilizado para alcanzar una expresión coloquial, apta para la expresión de las inquietudes políticas y para dar cuenta de la mediocre realidad de cada día, lo que condice con la «irrupción de la actualidad», la "transición entre el psicologismo y el sociologismo» y el «avance del coloquialismo y del prosaísmo» que sirvieron a Yurkievich ${ }^{14}$ para caracterizar a la poesía del momento. Esa orientación se acusó también en poemarios de factura distinta, como Poesía de paso, del chileno Enrique Lihn (premiado en 1966), y Canto ceremonial contra un oso hormiguero, del peruano Antonio Cisneros (premiado en 1968): un espíritu común los animaba, derivado de la desacralización del poeta y la poesía, del humor corrosivo que disimulaba la frustración, de la voluntad de prescindir de cualquier boato retórico o - caso de Cisneros- de neutralizarlo mediante su aplicación a motivos vulgares y pedestres. La personalidad indudable de estos poetas no evitaba que su éxito en Cuba resultase también significativo. Lihn, por entonces «antinerudiano recalcitrante, algo obsesivo» ${ }^{15}$, destacaba por su adhesión a la revolución cubana y su amistad con el grupo de la Casa de las Américas, dirigido por el «sargento Retamar» $(\mathrm{CV}, 410)$. En cuanto a Cisneros, que en sus Comentarios reales había recurrido a la ironía y el sarcasmo para revisar el pasado peruano, elegía ahora un título que remitía a otro de Neruda como si se tratase de resaltar las diferencias entre la novedosa narratividad coloquial de su poemario, la contención verbal con que daba cuenta de su voluntad desmitificadora, y las grandes pretensiones de una poesía caudalosa que parecía pertenecer al pasado.

Aunque en ese proceso influyó la necesidad de hallar nuevos recursos expresivos, cabe suponer que la poesía hispanoamericana se alejó de Neruda en la medida en que entraba en crisis una visión determinada de América: la del Neruda cosmogónico que coexistió en Canto general con el Neruda político e histórico nacido al calor de la guerra civil española. Esa visión de América probablemente no fue ajena a su estancia en México, que quizá merece más atención que la recibida hasta ahora. Allí trabó amistad con Diego Rivera, quien había ayudado a León Trotski a encontrar asilo en aquel país y ahora le demostraba una abierta hostilidad, y con David Alfaro Siqueiros, que había participado en un atentado fallido contra el político soviético ${ }^{16}$, asesinado finalmente por Ramón Mercader el 21 de agosto de 1940. La relación de Neruda con los comunistas mexicanos no facilitaba su acercamiento a la visión de México promocionada por André Breton, quien (precisamente cuando elaboraba con Trotski el manifiesto "Por un arte revolucionario independiente») lo había definido como el lugar surrealista por excelencia, surrealista 
«en su relieve, en su flora, en el dinamismo activo que le confiere la mezcla de sus razas, así como en sus aspiraciones más altas», entre las que se contaba «la de acabar con la explotación del hombre por el hombre» ${ }^{17}$. Pero las diferencias políticas no impedirían que el poeta resultase afectado por una atmósfera dominada por la exaltación de lo primitivo, exaltación potenciada por escritores surrealistas que visitaron el país o residieron en él, de Antonin Artaud a Benjamin Péret, o por pintores como Wolfgang Paalen; una exaltación que determinaba profundamente la visión de lo indígena, y que era compartida por muchos de los que frecuentaban su oficina consular y su residencia ${ }^{18}$. "México, con su nopal y su serpiente; México florido y espinudo, seco y huracanado, violento de dibujo y de color, violento de erupción y creación, me cubrió con su sortilegio y su luz sorpresiva» (CV, 213), había de recordar en sus memorias. «México, el último de los países mágicos; mágico de antigüedad y de historia, mágico de música y de geografía» (CV, 214), insistiría evocando el territorio en que empezó a descubrir las peculiaridades de la realidad americana.

No le faltaron ocasiones para perfilar la visión de América que necesitaba. En 1941 visitó Guatemala, aprovechando el tiempo de suspensión en sus funciones de cónsul con que fue castigado por proporcionar a Alfaro Siqueiros un visado para viajar a Chile. Allí trabó amistad con Miguel Ángel Asturias, que aún no había conseguido publicar El Señor Presidente, pero contaba ya con la experiencia de París y las Leyendas de Guatemala. En sus memorias había de recordar el estrecho camino que hubo de recorrer en aquel viaje, un camino que lo deslumbró «con sus lianas y follajes gigantescos, y luego con sus plácidos lagos en la altura como ojos olvidados por dioses extravagantes; y por último con pinares y ríos primordiales en que asomaban como seres humanos, fuera del agua, rebaños de sirénidos y lamantinos» (CV, 220). Al concluir su estancia en México, Neruda estaba convenientemente preparado para la visita a Machu Picchu que realizó en 1943, en su viaje de regreso a Chile. «Qué buen sitio para comer un cordero asado», parece que dijo ante las célebres ruinas, quizá para ocultar su verdadero estado de ánimo ${ }^{19}$. «Me sentí infinitamente pequeño en el centro de aquel ombligo de piedra; ombligo de un mundo deshabitado, orgulloso y eminente, al que de algún modo yo pertenecía. Sentí que mis propias manos habían trabajado allí en alguna etapa lejana, cavando surcos, alisando peñascos» (CV, 235), precisaría muchos años después. Entre quienes lo acompañaron en su visita a esas ruinas incaicas se encontraba José Uriel García, quien al reeditar El nuevo indio en 1937 no había modificado sus opiniones sobre la condición telúrica de los indígenas, profundamente ligados a la geografía de la sierra, aunque introdujera las correcciones exigidas por un tiempo en que las minorías intelectuales habían de abandonar su pedestal "para confundirse con las masas, marchar acordes con ellas y extraer de las injusticias de su situación, que son las injusticias de la historia mal encaminada, del régimen opresivo que sufren desde épocas remotas, los nuevos ideales realmente nacionales» ${ }^{20}$. Neruda había leído un discurso en su honor a fines de 1939, en la comida que se le ofreció en Lima como senador electo por la Coalición Obrera Peruana ${ }^{21}$. Su compañía probablemente contribuyó a que el poeta pudiese sentirse chileno, peruano, americano, a que encontrase inspiración para escribir "Alturas de Macchu Picchu" y el impulso necesario para avanzar en la realización de su Canto general.

Bien pudo reforzar esa visión de América en Brasil, cuando viajó a São Paulo en julio de 1945 para participar en el homenaje a Luis Carlos Prestes, que volvía a la libertad después de más de diez años de prisión. Para entonces había elaborado ya la concepción de la poesía que había de imponer con Canto general, y podía proyectarla sobre los demás: «Gabriela lleva en su obra entera algo subterráneo, como una veta de profundo metal endurecido, como si las angustias de muchos seres hablaran por su boca y nos contaran dolorosas y desconocidas vidas» (DP, 60), declaraba el 20 de noviembre de 1945 al celebrar el Premio Nobel concedido a Mistral. Ése era el propósito que había animado "Alturas de Macchu Picchu", escrito en agosto y septiembre de ese año: el poeta quiso ser allí la voz de los indígenas, hechos del barro de América y acordes con la naturaleza primordial que sustentó su vida. Otras secciones de Canto general se encargarían de exaltar esa América de los «ríos arteriales» frente a «la peluca y la casaca», frente a los colonizadores
Véase Rafael Heliodoro Valle, "Diálogo con André Breton", Universidad, núm. 29, junio de 1938, págs. 5-8 (6-7). Neruda era miembro destacado de la Alianza de Intelectuales de Chile por la Defensa de la Cultura, que desde 1937 imponía en el ambiente literario de su país los criterios stalinistas del Partido Comunista, y tenía pruebas recientes de la hostilidad de los surrealistas chilenos (fieles a Breton), quienes en julio de 1940 trataron de boicotear el homenaje de despedida que le ofreció la Universidad de Chile al ser nombrado Cónsul General en México, y luego dedicaron a ese incidente y a esa enemistad casi la totalidad del número 4 de su revista Mandrágora.

\section{8}

Entre ellos se contó Fernando Benítez (véase Volodia Teitelboim Neruda, Madrid, Ediciones Michay, 1984, pág. 212), quien años después, con "En el principio era el mito" (Cuadernos Americanos, VII, núm. 6, noviembre-diciembre de 1948, págs. 50-80), dio un notable impulso a la visión de América como resultado de la fantasía europea, a la vez que situaba el mito en los cimientos de la vida americana.

19

Véase Margarita Aguirre, Las vidas de Pablo Neruda, Buenos Aires, Grijalbo, 1973, pág. 215.

20

José Uriel García, El nuevo indio. Ensayos indianistas sobre la sierra surperuana, Cuzco, Editorial H. G. Rozas Sucesores, segunda edición corregida, 1937, pág. 2.

21

Ese discurso se publicó en Santiago, en el núm. 30 del semanario Qué hubo, el 2 de enero de 1940. Véase Hernán Loyola, "La obra de Pablo Neruda. Guía bibliográfica", en Pablo Neruda, Obras completas, III, pág. 1013.

Pablo Neruda, poesía y política TEODOSIO FERNÁNDEZ 

461.

\section{3}

Neruda no simpatizó con el escritor cubano, al menos después de la famosa carta de 1966. A ambos, sin embargo, se les reveló una América semejante -al poeta en Machu Picchu, al novelista en Haifí, en el mismo año 1943-, signada por la presencia de lo desmesurado y lo insólito. Las convicciones de Carpentier sobre lo real maravilloso americano son sobradamente conocidas. Según Neruda, «todo lo mágico surge y resurge siempre en México. Desde un volcán que le empezó a nacer a un campesino en su pobre huerto, mientras sembraba frijoles. Hasta la desenfrenada búsqueda del esqueleto de Cortés, que según se dice descansa en México con su yelmo de oro cubriendo secularmente el cráneo del conquistador. Y la no menos intensa persecución de los restos del emperador azteca Cuauthémoc, perdidos desde hace cuatro siglos, y que de pronto aparecen aquí o allá, custodiados por indios secretos, para volverse a sumergir sin tregua en la noche inexplicable» (CV, 231). Tampoco carece de interés su interpretación de las manifestaciones más sobresalientes del caudillismo latinoamericano: «En la fauna de nuestra América, los grandes dictadores han sido saurios gigantescos, sobrevivientes de un feudalismo colosal en tierras prehistóricas...» (CV, 243). y depredadores que asolarían ese territorio virgen, sin ignorar que esa «sauria escamosa América», "patria selvática» en la que «el gato y la escorpiona fornicaron», también fue capaz de engendrar traidores numerosos ${ }^{22}$.

Acorde con las exigencias de su tiempo, la visión de América ofrecida en Canto general muestra no pocas coincidencias con la recreada en Los pasos perdidos por Alejo Carpentierr $^{23}$. La obra de Neruda contribuyó sin duda a construir el territorio de la magia y el mito que la exitosa novela hispanoamericana había de divulgar a partir de esos años. Pero a la luz de los planteamientos revolucionarios, cada vez más radicalizados en Cuba, esa visión de América pronto iba a resultar obsoleta. El proceso seguido por la narrativa ayuda a entenderlo así: a medida que avanzaba la década de los sesenta, las novelas cubanas que parecían más acordes con la línea oficial -obras como Memorias del subdesarrollo (1965), de Edmundo Desnoes, y Vivir en Candonga (1965), de Ezequiel Vieta, hasta culminar en La última mujer y el próximo combate (1971), de Manuel Cofiño Lópezproponían con claridad creciente un discurso ajeno a las tentaciones "metafísicas» de la América mágica o mítica (una América al margen de la historia), y se negaban a asumir la identidad americana en tales términos.
Neruda tenía otros proyectos y la necesidad de buscar nuevos caminos, como pronto demostraron Los versos del capitán y Odas elementales, pero el éxito de Canto general fijó como suya la visión de esa América del origen y de algún modo mítica. Esa visión encontró continuidad en obras que quisieron ser el canto de los países en que surgían, como Nuevo Mundo Orinoco, del venezolano Juan Liscano, o Los cuadernos de la tierra, en que Jorge Enrique Adoum quiso trazar el itinerario del hombre ecuatoriano, o, ya a fines de los sesenta, Poemas para un pueblo, del boliviano Pedro Shimose, quien con Quiero escribir, pero me sale espuma pronto había de constituir en sí mismo un nuevo ejemplo del tránsito señalado hacia Vallejo. El coloquialismo o conversacionalismo de los poetas cubanos parecía situarse en las antípodas de las actitudes proféticas de Neruda y sus herederos, contra las que buscó antecedentes y soluciones variadas. Sus necesidades expresivas lo exigían, pero no deja de resultar sorprendente que la revolución fuese uno de los factores que llevaron la poesía lejos de quien había representado mejor que nadie el compromiso del escritor con la difícil realidad latinoamericana. 